\title{
"Feeling Less Than a Second Class Citizen": Examining the Emotional Consequences of Poverty in New York City
}

\author{
Samira Ali ${ }^{1}$, Ozge Sensoy Bahar ${ }^{2}$, \\ Priya Gopalan², Karolina Lukasiewicz², \\ Gary Parker², Mary McKay², and Robert Walker ${ }^{3}$
}

\begin{abstract}
It has been argued that individuals living in poverty are shamed, and thus, experience it in various social and institutional spaces. However, little is known about this dynamic in the United States. This study examined the relationship between poverty and shame among individuals living in poverty. Individual semistructured interviews were conducted with 60 participants in New York, NY. The results reveal that participants experience shame, anger, and frustration in their roles as (a) caregivers when being unable to provide material items and trying to keep up with others in society and (b) social welfare recipients when at the welfare office and accessing welfare benefits. Despite experiencing such debilitating emotions, participants formulated and used strategies to manage these feelings and situations. These findings point to the role of social and institutional practices in shaping emotions.
\end{abstract}

\footnotetext{
1 University of Houston, Houston, TX, USA

${ }^{2}$ New York University, New York, NY, USA

3University of Oxford, Oxford, UK

Corresponding Author:

Samira Ali, University of Houston, Graduate College of Social Work, 3511 Cullen Boulevard, Room 402, Houston, TX 77204-4013, USA.

Email: sbali3@central.uh.edu
} 


\section{Keywords \\ family policy, qualitative, poverty/welfare, parent/child relations, family processes}

\section{Introduction}

\section{Conceptualizing Poverty (Research) and Beyond}

Scholars have started to uncover the impact of poverty on individual health and well-being over the past decade (Alkire \& Foster, 2011; Dean, 2010; Lister, 2004; Tomlinson \& Walker, 2009). An emerging body of research argues that stigma, externally imposed acts or processes of shaming, and shame, an internally felt emotion, are associated with adverse outcomes, such as mental illness and lower self-efficacy among others (Jo, 2013; Mak, Poon, Pun, \& Cheung, 2007; Walker, 2014). While social welfare policies are developed to provide a safety net, they in fact, have the potential to stigmatize and further marginalize individuals. Thus, it becomes increasingly important to examine the relationship between poverty and the role of policies, policy practices, and social norms, in shaping experiences of shame. Uncovering this relationship and the ways in which it manifests in individuals' lives can lead to the development of policies and practices that respect one's dignity rather than perpetuate shame.

\section{Poverty, Shame, and Stigma}

Shame, a self-conscious emotion, is a negative assessment of the self in relation to one's own aspiration as well as the social expectations (Gubrium, Pellissery, \& Lødemel, 2013). Scholars have found that shame reduces selfesteem and dignity (Lister, 2004). Stigma is the stereotyping, discrimination, and labelling and occurs when power is imposed on an individual (Goffman, 1963; Link \& Phelan, 2001). Stigma can be on an (a) institutional level, where it is practiced through intentional components of policies that reflect political ideology (Goffman, 1963; Jacoby, 1994; Lister, 2004; Walker, 2014) or (b) on a social level, such as disapproval from society when a group deviates from the norms (shaming performed by other members of society). Stigma can also take the form of microaggressions, such as subtle acts of aggression and/or discrimination). In the context of poverty, stigma and shame are interconnected but distinct experiences with specific emotional responses and consequences (Chase \& Walker, 2013; Walker, 2014).

These forms of stigma often result in the psychological emotion of shame. It has been argued that the fear of being shamed encourages individuals to adhere to social norms, culture, and other predetermined ways of life to con- 
form to behavioral expectations of society or a community (Walker, 2014). Once these norms are broken, one bears the risk of being shamed, and thus feeling ashamed, which is a sense of inadequacy and the belief that the person is not valued as a human (Chase \& Bantebya-Kyomuhendo, 2014). In other words, shame is externally imposed on persons experiencing poverty by institutions and society in the form of stigma when individuals fail to live up to set forth expectations (Walker, 2014). This social and economic exclusion can lead to emotional consequences and have been found to be associated with poor health and well-being outcomes (Hatzenbuehler, Phelan, \& Link, 2013; Link \& Phelan, 2014; Mak et al., 2007). In sum, and for the purposes of this study, stigma is conceptualized as the active process of external shaming and the psychological emotion of shame as its manifestation and consequence.

Globally, there is growing evidence that shame is experienced as a consequence of poverty (Walker, 2014). In a recent study examining the relationship between poverty and shame in rural Uganda and India, urban China, Pakistan, Korea and the United Kingdom, and small town and urban Norway, scholars found that despite the vastly different material conditions, shame was associated with poverty (Walker et al., 2013). Though these lived experiences of poverty were socially and culturally nuanced, shame manifested through withdrawal, despair, depression, and thoughts of suicide and possibly contributing to the perpetuation of poverty. This poverty-related shame was often imposed by those who were not in poverty through negative attitudes, which in turn framed public discourse and policies as well as the implementation of policy programs. Thus, social welfare policies and programs can mediate shaming processes (Gubrium et al., 2013). While they can reduce shaming and strengthen dignity, they can also exacerbate feelings of shame, and as a result, work counterproductive to their objectives.

\section{Why Examine Poverty and Shame in the Context of the United States?}

The poverty rate continues to increase in the United States. Nationally, the poverty rate was $14.8 \%$ in 2014 , totaling about 46.7 million people, and $21.1 \%$ for children younger than 18 years (U.S. Census Bureau, 2015). Specifically, in New York City (NYC), the site of this study, the child poverty rate is the highest in 10 years, with about $31 \%$ of children living in poverty. Additionally, about 1 in 5 families live in poverty in NYC (U.S. Census Bureau, 2014). The United States has the highest rate of poverty among affluent democracies (Brady, Fullerton, \& Cross, 2010) and profound segregation by race (Quillian, 2012). The U.S. neoliberal social policies over the past 30 years have set the stage for the current social welfare state. The impetus for the 1996 welfare reforms, the passage of the Personal Responsibility and Work Opportunity Reconciliation 
Act, included "blaming the poor" for their material situation, dependency on welfare, and not entering the labor market. The welfare reform doubled the percentage of disconnected low-income mothers, specifically those who did not work but who also do not receive welfare (Blank \& Kovak, 2008). In sum, the United States has a history of developing and implementing stigmatizing means-testing tools, which has implications for policy, policy practice, and the ways in which individuals are treated.

Despite the strong stigmatization of people in poverty, only a handful of studies in the United States have examined shame in the context of poverty. These studies have described general experiences of people living in poverty and their coping strategies, without particular discussion on the psychological element of the emotions experienced (Halpern-Meekin, Edin, Tach, \& Sykes, 2015; Newman, 2000; Nicolas \& JeanBaptiste, 2001; Power, Cole, \& Fredrickson, 2011). However, this research falls short in understanding the ways in which families living in poverty experience shame, which can result in many adverse conditions, such as mental health issues and being stripped away of basic dignity.

\section{Current Study}

Given the gap in research on the relationship between poverty and shame in the United States and its potential implications for social welfare policy, this study examined individuals' experiences with living in poverty. More specifically, it explored the emotions that living in poverty invoked, with a specific focus on shame, the contexts in which these emotions were experienced, and the ways in which the feelings and situations were managed and negotiated by those living in poverty. A qualitative methodology was used to better understand individuals' experiences with poverty and the ways in which they made meaning of those experiences (Padgett, 2008).

\section{Method}

\section{Setting, Sampling, and Recruitment}

Participants were recruited from three neighborhoods that were among the 15 most impoverished zip codes in NYC, with an average poverty rate between $30 \%$ and $40 \%$ (Citizens' Committee for Children, 2012). Comparatively, the national poverty rate in the United States is just below $15 \%$ (U.S. Census Data, 2015). Participants were eligible for the study if they (a) had at least one child who resided with the participant, (b) received at least one type of social welfare benefit, and (c) lived in the three high-poverty zip codes in NYC. Participants were recruited through the assistance of the McSilver Community Collaborative Board (CCB), which consists of 30 members 
including urban youth, parents, representatives from community-based agencies, and researchers. CCB is a partnership between community members and researchers that implements research projects on prevention and intervention services for urban youth and their families. Purposive sampling was used to identify and screen potential participants. New York University Institutional Review Board approved the study.

\section{Sample Characteristics}

The study sample consisted of 60 participants. Most were female (89\%) and ranged in age from 19 to 73 years with an average age of 39 years. Most of the participants $(85 \%)$ were born in the United States. A little more than half of the sample identified as African American (56\%) and about a third identified as Hispanic/Latino/Central American/Puerto Rican/Dominican (36\%). More than half of the participants identified as being single. Less than $20 \%$ were married, and fewer than $20 \%$ were in a relationship. On average, participants had two children. Most of the participants received Supplemental Nutrition Assistance Program (89\%) and a little less than half received Temporary Aid to Needy Families (43\%). Most of the participants received government health benefits (87\%). Almost half of the sample lived in a form of government-subsidized housing (NYC Housing Authority or Section 8 ). More than $50 \%$ of the sample noted that they were not able to save every month.

The specific demographics of each participant quoted are included in parentheses at the end of the quote and are in the following order:

Participant ID, age, gender (F for female, $\mathrm{M}$ for male), ethnicity/race (AA = African American, $\mathrm{PR}=$ Puerto Rican, $\mathrm{CA}=$ Central American, and $\mathrm{D}=$ Dominican), and number of children in their custody.

\section{Data Collection}

In-depth semistructured interviews were conducted with 60 participants. The interviews were conducted either at community centers or at the CCB offices located in the neighborhoods. Consent was obtained after the interviewer described the study in detail, usually on their first meeting. Participants received $\$ 30$ and a round trip subway card. Interviews ranged from 20 minutes to 1 hour and 15 minutes. Six trained interviewers, including the first author on this article, conducted the interviews.

The individual interviews were based on an interview guide that asked about participants' current challenges in life, including their financial situation, emotions/reactions evoked by those challenges, and ways in which they coped and managed such emotions and situations. More specifically, questions included, but were not limited to "What are the biggest challenges for 
your family resulting from financial situation?" "How do you think your finances affect your children?" "Are there any ways in which your current circumstances have affected how you feel about yourself?" "What was your experience accessing social support service?" "What was your experience of interacting with service providers?" "How does the idea of applying for a new benefit make you feel?"

\section{Data Analysis}

The interviews were audio-recorded, transcribed verbatim, and loaded into Dedoose Version 6.1.18 to manage and code the data (SocioCultural Research Consultants, LLC., 2015). We used thematic analysis as described by Boyatzis (1998). As suggested by Boyatzis (1998), data analysis began by coding the data through engaging in an iterative process of identifying key words and concepts and reflecting (see below for details on the process). To ensure that the quality of the phenomena was captured, various questions were reflected on, including but not limited to "How should this phenomenon be captured and called? "How are these data going to be recognized?" Coding was validated using multiple coders. Furthermore, codes were grouped into themes and subthemes and were finalized based on patterns that emerged during the data analysis process.

Coding Process. Three researchers, all authors on this article, coded and analyzed the data. The research team first read nine transcripts (three from each zip code) to get a thorough understanding of a subsection of the data. Then, they independently coded one transcript and met to discuss the codes. Open, in-vivo, and theoretical coding were all used in this initial process and throughout the coding process (Glaser \& Strauss, 2009). Both a priori, sensitizing codes (e.g., shame) and codes that were grounded in the data such as other emotions of anger and frustration were used in the coding process (Miles \& Huberman, 1994). Two additional transcripts were then coded using the existing codes as well as additional codes that each of the researchers deemed appropriate. At the next stage, three of the same transcripts were coded by the research team. Through various discussions and iterative coding exercises, a codebook was developed. Disagreements on codes were resolved by revisiting the data for further examination and clarification during research team meetings. Code definitions were revised and refined accordingly. A fourth transcript was coded using the codebook to ensure that the codebook was effective. As a result of this iterative process, four major themes (with subthemes) were identified (see Figure 1). 
Figure 1. Poverty and Shame Conceptual Model.

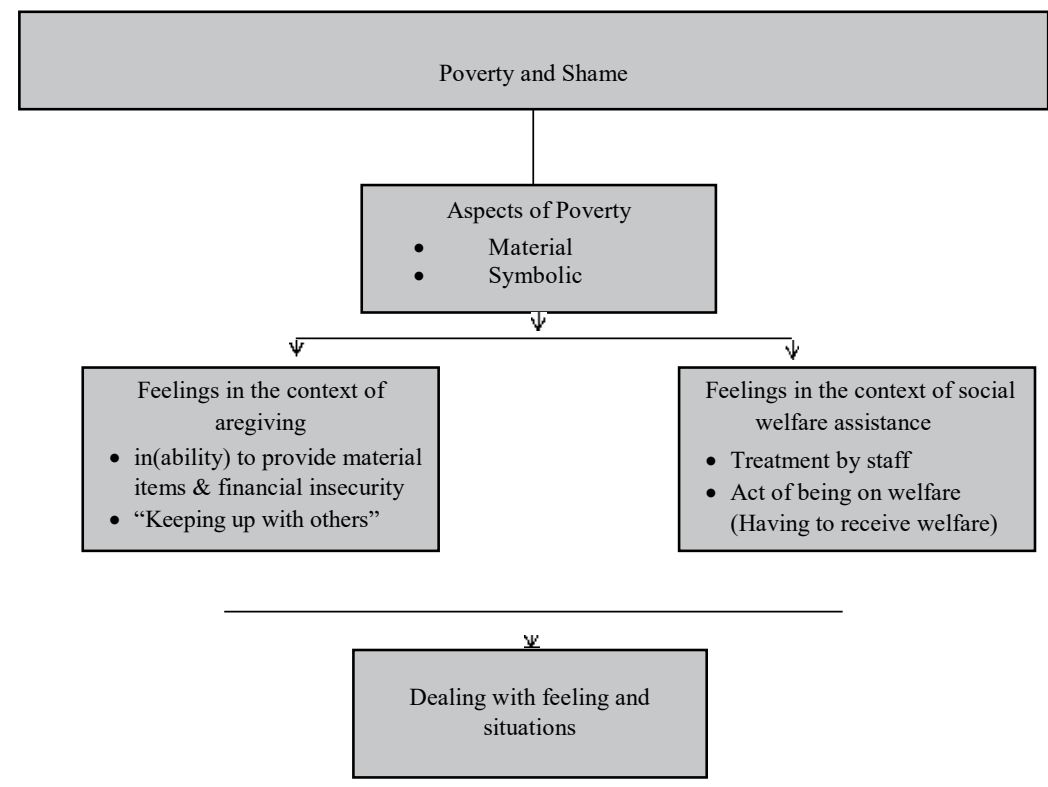

Once the codebook was finalized, the researchers coded 20 transcripts each. While the coding was done independently, the research team met weekly to discuss the analysis. To ensure rigor, memos were used during the interview process as well as during the coding and analysis (Padgett, 2008). Peer debriefing was used by presenting the codes and results to two McSilver CCB community members, which allowed to test and defend emergent hypotheses, assess their plausibility to a disinterested debriefer, and explore aspects of the data that may otherwise remain implicit.

\section{Results}

The results reveal that participants experienced both material and symbolic aspects of living in poverty which shaped their emotions and the ways in which they dealt their feelings and situations. They experienced shame, anger, and frustration in their roles as (a) caregivers-when they were unable to provide material items and when trying to keep up with others in society and (b) social welfare recipients - when they were at the welfare office and while accessing welfare benefits. Despite experiencing such debilitating emotions, 
participants formulated and used strategies to manage these feelings and situations.

\section{Material and Symbolic Aspects of Poverty}

Participants discussed both material and symbolic aspects of living in and dealing with poverty. Unstable housing due to inability to pay rent or loss of access to shelter/temporary housing, challenges with shelter system, and/or food insecurity were commonly experienced. Many also discussed the inability to pay for transportation, utility bills, and health care. For example, one mother of four children voiced her challenges with putting food on the table for her children:

There's time where I just run out and I don't have like for week in a half, I will not have milk. I will not have bread. I will not have eggs for my kids. Like that - them last—last week of the month and the first week of the month, those two weeks, I be struggling trying to make-looking for something to give to my kids. (A202, 41, F, PR, 2)

The symbolic aspects of living in poverty included the ways in which individuals were constructed and stigmatized by institutions and the society in general, including the media, people of different classes, and welfare institutions. When asked about the ways in which she was constructed by society, one participant exclaimed,

Um, that we're lazy, we don't do anything, we just want to sit on our asses and collect public assistance. That's how I feel. That's what I think. (K309, 28, F, AA, 1)

Discussing her thoughts in detail about the ways in which people on public assistance are constructed, she also noted:

Bum, I guess homeless. Nasty. I guess they're lazy, you know, good for nothing, like.

Participants were aware of the negative stereotypes (e.g., violent or undesirable) their neighborhoods were associated with. Challenging the stereotype about people living in poverty being lazy, one participant discussed the reality of most of her neighborhood:

[People in this neighborhood] work. They go to school. They have an actual life. You don't see them in the street, and those are the majority of the people. The minority of the people that you see on the street those are 
they make the small fraction of the community. ... That's just a number of people that just are not working. . . . But I think in people's mind.

They think poor neighborhood people just don't do anything, and that's not the case. So, you take the good with the bad. (A603, 40, F, D, 4)

Overall, participants shared experiences regarding both the material and symbolic aspects of poverty. The ways in which participants were negatively constructed and consequently treated, along with the experiences with poverty, often triggered a range of emotions, including shame, anger, and frustration both as caregivers and public assistance recipients (as discussed in the following sections).

\section{Feelings in the Context of Caregiving}

Inability to Provide Material Items and Financial Insecurity. Participants discussed the inability to fulfill social expectations attached to their caregiver roles, such as providing certain food or clothes for their children, having cash, and asking for help. In other words, participants felt that they were not able to fulfill the socially constructed roles of caregiving, such as providing certain things to their child. Such constructed failure was often deeply internalized, resulting in feelings of shame, anger, and guilt. A single mother of three teenagers who was chronically ill voiced that her biggest challenge was to provide them with enough food. Despite her illness, it was more important for her to have enough of food for her children, than for herself. When this sacrifice was, however, still insufficient, she felt "less than a mom":

The biggest challenge that I have is making sure everyone eats and I don't, which is not good . . . you have a big boy in your house whose appetite is - exceeds the amount of money we get. . . . It hurts me that I have to tell him "no" sometimes. . . Sometimes it makes me feel less than a mom because I'm not, you know, in the supermarket always replacing stuff. I hate the supermarket but you know, you got to go at some point. But I just-I hate telling my kids no, especially when it comes to food. (K307, 38, F, AA, 3)

While providing food for their children was not a major issue for some, certain foods were not affordable causing some participants to feel ashamed. A 70-year-old widow caring for two teenagers was not eligible for food stamps, and thus, she often used the food bank to provide enough food for her family. While she was able to put food on the table, she was concerned that it was "just plain food": 
I don't want this, you know. I had this every day this week, you know. And we don't want spaghetti tonight. We want chicken, we want fish, we want that. . . Y You know why we having beans and rice again tonight? . . . So it makes me feel kind of rough and that knowing that they want certain things, and it's just plain food to keep them alive. (A610, 70, F, AA, 2)

In addition to food-related challenges, some parents voiced feeling inadequate, angry, bad, or guilty about the inability to buy clothes that were needed or desired by their children. Because of the daily struggle to cover basic living expenses, one participant postponed the decision to buy her child a graduation suit. This resulted in very strong feelings of anger and guilt for the inability to fulfill her duties as a parent.

I started paying the bills and then I was like, "I'll get his suit on Monday. And I'll get his suit that day." And the money was going . . ., and buying stuff for the house, and getting them their shoes. When it came to almost the day of the graduation, I didn't have anything. I went berserk. I was like, oh my God, he's going to be without his clothes. . . . It took me and choked me. It took me to that point and I was like, "Oh my God. I'm bad. I'm bad because I'm not being on point with what I've got to do."

(DC703, 41, F, PR, 2)

Financial insecurity related to lack of cash also led to feelings of inadequacy, anger, or shame. When children realized their parents' financial situation, and for example, protested in public, it made them feel even more ashamed.

And it's embarrassing. And it's like, I be on a bus, or we be in, like, the store, or often times it's the Mommy, you dead serious? You only got two dollars? Really? Two dollars? And you know, she'll make a scene. She loud, too. So it's like, oh, my god, really? Like, in front of people. Oh, my god. (DC710, 24, F, AA, 3)

Financial circumstances forced caregivers to ask for help, which for some meant admitting being unable to fulfill their duties as parents. The emotional price for asking for help was high and included feeling bad, angry, or frustrated.

In addition to anger and frustration, many participants discussed feeling depressed or low. At times, such feelings were triggered by a change in the financial situation, such as loss of a job, and thus, being unable to buy things for their children that was once possible. After losing her job, one participant reflected on feeling depressed: 
It [losing job] kind of made me a little depressed because I'm used to working and always having a job, so it took a toll on me because, you know, I've got to be able to take in my son and make he gets everything he needs . . . it has really affected me emotionally. (D613, 23, M, AA, 1)

Losing her job was especially critical for this participant as it interfered with her ability to buy things for her children that she could once afford.

Participants' accounts illustrated that the negative feelings, including shame, often resulted from the social stigma of living in poverty and not being able to adhere to social norms of parenting. They were aware of the social expectations attached to the role of a caregiver and knew how much and what kind of material goods (e.g., food, clothes) caregivers "should" provide for their children. The fact that their children were aware of what parents "should" be able to provide them, was even more painful for some of the participants. Yet poverty limited their ability to fulfill social expectations regarding material goods that some caregivers thrived to meet, while others could not.

"Keeping Up With Others." The social pressure to keep up with others triggered a range of emotions. Some participants discussed feeling embarrassed or angry when their children expected them to keep up with others, such as family or community members who belonged to higher classes. The inability to participate in holiday parties or weekend activities like other family members and expose their children to such festivities was embarrassing for some. After a change in her financial situation, a mother discusses that she was not able to keep up with activities like before.

It's embarrassing because normally on holidays I have the family get together. I'm the one who cooks; everybody comes to my house with their kids. I can't do none of that. We can't celebrate nothing. . . . it's just totally embarrassing. (D109, 42, F, AA, 5)

Another mother discussed feeling sad when visiting their friend in Long Island because her daughter wanted a house "like that":

Yeah, I mean now she's telling me that she doesn't like that school that she wants to change schools. One day she told me, 'cause we ended up going to Long Island to my friend's house and she told me "Mommy, we should get a house like that. You know "cause it was with a pool and everything." [This made me feel] very sad. (K304, 41, F, SA, 2) 
However, this was not true for all the participants. Some participants said that they did not feel ashamed of their inability to keep up with others, because they felt they were already trying their best to support their children. Proud of being a single parent, one participant did not feel that she had to avoid others:

I don't avoid people. I'm a people's person. . . . I'll talk to everybody. Everybody knows me. They love me. ... They tell me I'm doing a good job taking care of my baby even though I'm doing it by myself. So I see that's a plus. So that makes me feel proud as a mom and as a single parent. ... I give myself a round of applause (Clapping). (K310, 33, F, AA, 1)

In sum, when the constructed social norms of keeping up financially with others was not adhered to, participants not only felt ashamed but anticipated that feeling. When caregivers broke the norms attached to their social roles and were reminded of that by their children, the feelings of shame were quite pronounced. In other instances, some participants did not feel ashamed because they felt that they were trying their best to provide for their children. Thus, the feeling of shame varied in the context of keeping up with others.

Dealing With Feelings and Situations in the Context of Caregiving. While participants described in detail the range of feelings they experienced in their roles as caregivers, most participants also discussed the ways in which they managed both these emotions and the situations that evoked them. They took the initiative and found ways to cope with feeling "depressed and down" because of their inability to provide for their children by engaging in relaxing activities (e.g., walking or listening to music) or spirituality. Describing the ways in which she managed depression, one participant discussed

There are times that I do become depressed. But I find ways to keep myself active. And I think to me that's the most important. ... When I would get depressed I would take walks with my kids on the boardwalk. We would just take walks. I would go visit my mother, because my mother was living out there, and she still does. My sister's living out there, and we visit them and go home and just find things to do. (A603, $40, \mathrm{~F}, \mathrm{D}, 4)$

Holidays often made it worse for parents and their children. Not being able to afford things that her children wanted for Christmas made one mother"very stressed out, very sad, very angry and everything." She stopped visiting her friends' houses for Christmas where her children could see, and then later ask for, things she would not be able to afford. 
Like Christmas, Thanksgiving and all that, I stay in my house with my kids. We'll eat, turn on the TV, play with them, that's it. I don't go to family members or anything like that. No, nothing. . . Y Yeah, my kids not to feel uncomfortable and so I don't feel uncomfortable because then you know, they'll make me cry that they're asking for things that I can't afford, you know. (K304, 41, F, SA, 2)

Her feelings led her to isolate herself and children from social interactions, which could ultimately hinder the building of social capital. By avoiding situations and/or places where her children could be exposed to things they wanted, she tried to minimize feelings of discomfort as well as anger, stress, and sadness that would arise from her inability to fulfill her children's wishes. Thus, this situation displays agency in terms of the ability to manage and negotiate situations that could be detrimental to both her and her children's emotions.

While some caregivers shared the predicament that they were in with their children, others thought that children should be shielded. A single mother of three talked about concealing her financial situation from her children. She thought that she needed to stay focused and continue to push herself to make it work.

I don't talk this to my 15 year old because she's the one that understand, I mean, she looks at me and she knows that she could feel it. ...

Sometimes she'll come to be she's like, "what's the matter, mom? You look sad." No, I'm good. I just had a bad day today, you know? Because I don't want to show her that. I want to show her that I'm strong and no matter what we go through in life, you just got to stay focus and you just gotta keep on pushing and pushing yourself. (DC701, 34, F, CA, 2)

Spirituality also served as a coping mechanism, particularly, "keeping people from going over the edge." Discussing a move with extended kin to alleviate the burden of paying rent, one participant discussed the role of spirituality in communicating with her children about their financial situation:

It's just too much. So you try to just make it with a prayer. . . I keep saying just hold on, don't let go before the blessing come and just trust God, that He already know what I'm going through. And if I just hold on and just wait on him He'll provide everything I need. . . . I've been talking to them for a long time and they understand that we just have to deal with what's in front of us and what we have for right now. (A607, 52 , F, AA, 1) 
Participants' narratives showcased the strategies they developed to deal with the strong emotions and challenges in their roles as caregivers. They primarily relied on more introverted strategies such as spirituality, avoidance, shielding their children from their financial situation, and/or meditative walks. However, they also pushed themselves harder to find jobs and/or turned to family and friends for support.

\section{Feelings in the Context of Social Welfare Assistance}

Shame, anger, and frustration in the context of experiences with welfare and the ways in which participants coped and managed such emotions and situations were discussed in relation to (a) the ways they were treated by welfare office staff and (b) the actual act of being on welfare.

Treatment by Staff. Most participants shared experiences of being shamed, humiliated, and belittled by the staff at the welfare offices, Human Resource Administration, Social Security, and Homeless Services offices. Some discussed feeling ashamed at their welfare appointments. Reflecting on an experience at the welfare office, a single mother of three young children explained how even filling out initial paperwork for public assistance made her feel "less than a second class citizen.”

The whole process is so frustrating but the people make it worse.... The staff, the security. It's just the - a mental thing of them not realizing that they can be up and down tomorrow as well. So I think if everyone treated everyone as an equal versus as a first class, second class, middle class ... the process of PA will be a lot easier ... you wouldn't feel ashamed versus feeling like you need a little bit of help for the moment. . . It was embarrassing because I didn't know what I was gonna do next. (503, 48, F, PR, 4)

Other participants described similar situations driven by microaggres-sions, which are subtle forms of aggression and/or discrimination. These microaggressions triggered feelings of shame at the welfare office.

It's the people that implement the work that make it hard for you because they don't want to put all the data in the computer and they just make you feel like trash. Like you're not worth nothing just because you're on public assistance. Not all of them are like that, but the majority of the 
ones that I had, that's the way that they treated the clients. (K311, 27, F, AA, 2)

These microaggressions rooted in welfare program implementation ultimately led the recipients to feel ashamed.

In addition to shame, dealing with the welfare office also left participants feeling angry and frustrated. A single, immigrant mother of four children discussed the treatment at the Human Resource Administration office and feelings she experienced almost made her leave the assistance, but the need to provide for her children gained the upper hand:

And you get frustrated. Some people do curse them out. Sometimes you be looking at what's going on like, they don't work-everybody's not on the same page. So, you get frustrated because there be times that I'm like, crying. I don't know what to do. I just want to leave it. I want to close it, but then if I close my case how I'm going to support my kids? So, you're in between-I don't know. It's hard. (S502, 37, F, D, 4)

Overall, participants described experiencing a range of negative interactions in welfare offices and discussed the intense emotional agitation that led them to consider the need for assistance.

Being on Welfare. Some participants felt that just being on public assistance was shaming and shameful. Many participants experienced shame through the external, institutional stigma, such as physical act of having to ask for help and accessing benefits. Reflecting on her experience, one mother discussed "swallowing her pride" so that she could get what she needed to feed her family:

When I went to apply, it was so, so hard and I said I'm going to swallow my pride. You know and bite my tongue and I'll hold myself and just gonna' sit there. And take the humiliation, the hurt, you know, whatever what they want to do with me. (DC704, 50, F, PR, 3)

Shaming arrangements, ones in which the act of "shaming," was institutionalized was often discussed. The public visibility of being a welfare recipient made many participants uncomfortable. A single mother narrated her experiences of being in the welfare line:

I think that's bad because people pass by and they're seeing you standing in line, you know, waiting in line and that you need help. Not everybody has to know your situation but you know, you stand in line 
and ... people are passing. And there's noisy people, neighbors that are noisy and they just want to be all in your business and they'll say hi to you but they're laughing behind you. They're like "Oh look, look at her." ... [It makes me feel] like shit. (K304, 41, F, SA, 2) Standing in line outside the welfare building exposed her to the world. The fact that the lines were long and moved slowly increased her chances of being seen by her "nosey" neighbors, making her more vulnerable to being "laughed behind." Others were shamed when they were at stores, making them visible to others when using food stamps. The feelings of shame primarily resulted from concerns about how other people might perceive them. When asked if she was embarrassed, one immigrant mother voiced

Sometimes when I go shopping for food . . . sometimes because I say well, I signed up for this assistance, it helped me and why the people looking to me like that when I'm doing something wrong or something bad? (D101, 52, F, SA, 2)

Others felt that such help was temporary or well-deserved because they had worked previously, and thus, did not feel ashamed. A grandmother raising an adolescent boy felt angry that she was not able to receive food stamps for her grandchild because they were for him.

This is for a child, not for me. You can't make a child work. . . I was never [embarrassed]. . . . I was more angry than anything. I was never embarrassed. Food is food. Like who's going to be embarrassed but. . . . But how could you deprive? It's like you were actually telling me . . . up ... stop. . . Y You're not going to get it. Get out of here. Next. (S506, 46, $\mathrm{F}, \mathrm{AA}, 1)$

Feelings around receiving public assistance changed over time. A mother discussed feeling ashamed when she first started to receive public assistance. Later, her perspective shifted:

At this point, no [I don't feel ashamed]. In the beginning, yes. . . I mean it didn't affect me. I just felt that I shouldn't be here, having to depend on the government to help me. But I'm grown. I have a kid. I can't depend on mommy because mommy has her own bills to pay. So I have to be independent. (K305, 33, F, PR, 1)

Being "independent," for her, meant that she stopped relying on her mother and started to take care of her own life. The assistance was perceived as a legally accessible tool that she had the right to use when in need. 
Experiences of being shamed in the welfare office by staff and frustration at the system and process involved in accessing benefits were triggers for emotional responses among all participants. Even if they did not feel embarrassed personally, recipients of welfare were upset and angry about the way they were treated.

Dealing With Welfare Staff and Being on Welfare. The major strategy participants used to deal with the staff attitude in the welfare office was to prepare themselves mentally for possible negative interactions and try to avoid getting into any conflict with the staff. Reminding herself to "put her pride aside," a married mother of two elaborated on her strategy because she needed the resources for her two kids.

I never came across people that speak to you as if you're below, you're beneath them, as if you don't know. And because you need certain things you've just got to put your pride aside - "I'm not going to say this to a person because at the end of the day I do need this. I'm not going to act like this because I do need this." I'm going to remember who I am but I'm going to remember that I still have two kids to feed. (D110, 24, F, AA, 2)

Despite the fact that she found the welfare staff's attitude to be "incredibly rude," she also realized that the only way she would be able to access services was if she did not get agitated by their comments while "remembering who she is."

While some participants mentally prepared themselves for potentially degrading situations, others were more proactive in advocating for themselves. One participant, a 46-year-old mother who lived with her two children, discussed at length her experience at the court.

So I put myself in the position that I was able to speak up more for myself. . . . I told the judge "I don't want to overstep my boundaries, I said, but there's more to this than what they're representing. And I intend for you not only to hear their side but to hear my side so that you can make a better judgment, you know." So I explained to the judge why I came, what I applied for public assistance was because I wanted to go to school. (S507, 46, F, AA/PR, 5)

Feeling voiceless when she was at the court the first time motivated her to defend her right to access welfare benefits the second time she appeared in front of the judge.

Another participant who lived with her 19-year-old daughter described how she called the commissioner numerous times to report on one supervisor at the welfare office: 
So they tell her, you shouldn't even be in here applying for welfare. And I called the commissioner on this woman. I reported this woman over 1000 times and this still — she's a supervisor and she's still sitting in there. Her coworkers have reported her. She's still there. And she try to belittlebelittle my daughter. And she was supposed to be opening our case. . . . [That made me feel] Anger . . Just mean, anger and disrespect. (S504, 48, $\mathrm{F}, \mathrm{AA}, 1)$

Her interactions with this particular supervisor made her feel angry and disrespected. The fact that no action was taken at the end by the welfare office further contributed to her "anger."

Some participants noted that they were familiar with their rights as welfare recipients and thus were able to stand up for themselves when dealing with welfare staff

And you shouldn't be sucking your teeth at me because I'm here for some help. I have court order papers they sent me to HRA to get a one shot deal to get emergency assistance. That's why I am here. (A202, 41, F, PR, 2)

Most participants preferred not to be on welfare if they had another option. One of the ways participants tried to get off public assistance was to keep sending multiple job applications and not get discouraged by rejections. For instance, a single mother of two children noted her job application experience for the past two years.

Ever since I applied for public assistance. ... This was last year in October, I've been sending my resumes, applying online and two years and I tell you, no luck. (DC701, 34, F, CA, 2)

This mother was in school to get her GED so that she could "better" herself and find a job that paid well enough to take care of her two children and not be dependent on welfare. Participants' narratives illustrate the ways in which they took ownership in managing their feelings and situations in the context of the welfare system. The main strategies that helped participants navigate their feelings and uncomfortable situations included avoiding situations, mentally preparing for certain interactions, praying or engaging in an activity, and seeking employment.

\section{Discussion}

The findings reveal that while people living in poverty experience shame, they also feel angry, sad, and frustrated in the context of being 
a caregiver and welfare recipient (see Figure 1). Results from this study in many ways mirror results from other places in the United States as well as other countries that examine the relationship between poverty and shame (Chase \& Bantebya-Kyomuhendo, 2014). Individuals experiencing poverty were concerned about similar issues; references to shame took place within similar areas of life (family/caregiving and welfare); and feelings of shame were similarly constructed. The neoliberal policies and ideological environment have constructed social norms on being a good mother, a good citizen, and labor participation. This social construction often led to the belief that to provide for one's child, labor participation was mandatory, and the inability to fulfill that expectation often led to various negative emotions. Shame and stigma often played out in these spaces. Specifically, we argue that stigma and shame were intricately connected, but operated in distinct ways and served different purposes. Stigma created divisions among caregiver that were (un)able to adhere to the social norms. Furthermore, stigma was imposed through microaggressions and other practices at the welfare office. As a result, shame(ing) was experienced due to the inability to adhere to the social norms of being a "good parent" or "independent citizen." Aware of the oppressive systems that enforced social norms, participants actively engaged and managed their situations and emotions regarding caregiving and welfare. Such findings have implications for policy development and practice.

\section{Feelings (and Dealing With) in the Context of Caregiving}

Fulfilling the social role of a caregiver was extremely important, and thus, the context in which shame was often experienced. The emotional toll of the social stigma on "inadequate" caregiving was very pronounced. Turning the public discourse on its head, many participants explicitly noted that challenges of providing material goods (food, shelter, etc.) to their children were related to structural issues and not inherent character flaws. People living in poverty did not succumb to the public/political discourse that people in poverty are lazy and feckless if not corrupt and criminal. Despite this realization, many experienced a range of emotions, such as "feeling less than a mom," feeling low, angry, and embarrassed. Furthermore, children were often aware of the material hardship their families experienced, and in some cases, put additional pressure on parents to keep up with social expectations.

Feelings of embarrassment and frustration were often triggered when individuals were unable to keep up with societal norms of higher economic classes. Some noted that such challenges motivated them to try to excel in their job or education. As such, social norms and often the external stigma 
can be conceptualized as drivers of internalized negative emotions as well as the positive ones, such as the motivation to keep up with others.

While the research aim was to better understand the relationship between poverty and shame, almost all participants discussed a wider range of emotions and the ways in which they dealt with those emotions, including engaging in activities, isolating themselves and their family, keeping their financial situation from their children, and moving in with extended family. Overall, many recognized that they were doing their best but were constrained by structural challenges that were out of their hands.

\section{Feelings (and Dealing With) in the Context of Welfare}

Negative experiences with the welfare system, such as intense external stigma, in the form of microaggressions, stigma and humiliation at the welfare office were widely discussed. Some, on the other hand, did not express feelings of shame rather they felt that welfare provided support for them in time of need.

Shame was often experienced at the welfare offices. Welfare employees declined to look up additional information in the system that would ultimately help their case and closed their case for unexplainable reasons. Such experiences led participants to feel that they were treated like a "second class citizen." This institutional stigma led some participants to internalize feelings of embarrassment and anger. Other studies have found that individuals often receive problematic treatment at welfare offices (Houser, Schram, Soss, \& Fording, 2014; Soss, Fording, \& Schram, 2011), leading to depressive symptoms at times (Dooley \& Prause, 2002). This study adds to the current scholarship by connecting such treatment to the feelings experienced (e.g., shame, anger) during those situations.

The fact that that individuals were receiving welfare benefits also contributed to feeling ashamed. Similar to Rogers-Dillon's (1995) findings, the physical act of actually applying for welfare, waiting in line, and the public visibility of using food stamps triggered embarrassment as well as anger. "Shaming arrangements" were made within the welfare system, such as waiting in lines outside welfare offices while being watched by their neighbors and/or others. Such stigma was further reinforced by the social stigma on receiving welfare during these "public display" instances that violated one's privacy by revealing their status of "being on welfare" to the outside world.

Similar to other studies, we found that while individuals discussed structural limitations, they made individual efforts, displayed agency, and articulated ways to manage and negotiate their situations as well as emotions (Lavee \& Benjamin, 2016; Seefeldt, 2017). With that said, most managed the microaggressions and overall bad treatment in the welfare offices. Strategies such as mental preparation, especially since many had spent 
countless hours and days at welfare offices and "remembering who one is" were often used. Negative treatment motivated some to advocate for themselves and try even harder to find a job. Thus, while participants did want to get off of welfare, welfare policies and practices often impede their ability to obtain employment.

\section{Grounding the New York Experience in the Global Context}

In this study, like in other countries where poverty and shame nexus has been examined (India, Pakistan, China, Great Britain, South Korea, and Norway), participants were concerned about obtaining food, clothing, and shelter, being able to live up to one's own and social expectations, and having financial independence (Chase \& Bantebya-Kyomuhendo, 2014). Despite the similarities, results in this study differed in the ways in which participants reported and responded to shame. While some discussed feeling ashamed in the context of caregiving and as welfare recipients, most participants brought up other emotions as well, such as anger and frustration. Since taboos surrounding these emotions often lead to denial, people who might experience such feelings rarely directly reference feelings associated with shame.

Instead, some scholars have argued that people refer to other related feelings such as embarrassment, guilt, humiliation, or shyness - all originating in threats to social bonds (Scheff, 2003). While shame might in fact trigger other emotions (guilt, anger, etc.), we found that these other emotions were either discussed in isolation from shame or their connection to shame was unclear.

The global poverty and shame studies identified three major responses to shame: (a) trying to be "normal," (b) avoiding normal, and (c) resisting the normal. Compared with other countries, participants in this study seemed to focus more on the first reaction, which included coping. Most participants did not report feeling powerless, rather they expressed ownership over their lives by managing and coping with their situations and emotions through dealing with the bureaucracy or by resisting it.

The second response to shame identified in the global poverty and shame studies includes withdrawal and avoidance of social relations potentially precipitating shame. In this study, similar to other countries, it was manifested mainly in response to caring for children and in the context of welfare. In different countries, however, this response to shame was also expressed in the context of workplace. Because of the sampling procedure, participants were mostly unemployed, thus, rarely referred to the workplace. The third response to shame - resisting the normal - identified in other countries included "othering." This reaction was also present in New York when participants differentiated themselves from those who "misused" the system. 
Whether people in this study experienced less shame and coped with the feeling better than in other countries, or whether they are less likely to report shame and are more likely to report coping requires further inquiry.

Comparisons across qualitative studies are difficult to make with respect to essentially quantitative concepts such as "more" or "better." However, it is possible that this study yielded different results because of the individualistic nature of the U.S. society that have been further intensified by the neoliberal policies, namely, since the 1996 shift in social welfare policy. In collectivist societies, such as some of the other countries in the global poverty and shame studies, shame has a stronger social dimension and consequently reinforces obedience to social roles (Chase \& Bantebya-Kyomuhendo, 2014). American culture is built on a meritocracy myth (McNamee \& Miller, 2009), that is, getting ahead based on individual efforts and abilities. Even though there is much higher awareness of structural determinants, the meritocracy myth is still alive. Thus, participants might have been less likely to report shame and more likely to narrate the ways in which they coped.

\section{Limitations}

The interviews were cross-sectional (conducted at one time point), limiting the understanding about how emotions and management of those emotions and situation change over time. This limitation could have also interfered with developing rapport with participants, causing hesitation to reveal their actual feelings especially on shame. Future studies should consider interviewing participants over a period of time, at multiple time points. Second, these findings are unique to the specific zip codes in NYC, thus cannot be generalized to the rest of the United States. Third, all the participants were currently receiving welfare support, so there is limited comparative understanding about those who were not on welfare but still experiencing poverty. Fourth, we did not ask questions related to racial or ethnic disparities and given the racial and ethnic composition of the neighborhoods, the sample is composed of mainly two racial/ethnic groups. Finally, there is an overrepresentation of females in our sample due to the disproportionate amount of females (compared with males) who care for children.

\section{Conclusion}

This study draws a conceptual link between experiences of living in poverty and feelings of shame, particularly, in the context of being a caregiver and a welfare recipient. Specifically, we found that macro and mezzo structures and practices, such as policy practices, do, indeed shape the ways people feel about themselves and their situation. Living in poverty triggers painful emotional responses, including shame, anger, guilt, and frustration. Feelings of shame 
linked to poverty are personally experienced but externally imposed and shaped by social institutions, also referred to as external stigma. This external stigma takes the form of social control, deterrence, and even punishment and is deliberately imposed by the institutions and the people who represent them. Given our findings, policymakers should consider ways in which to enhance dignity and reduce shaming language and practices when developing social welfare policies. This could include revising the language used in the policy documents to enhance dignity and training street-level bureaucrats in more dignity-related practices. Furthermore, the study adds to the existing evidence that individuals living in poverty are already hurting and the stigma delivered through welfare institutions and ideologies add to their pain while infringing their human rights.

\section{Authors' note}

Gary Parker and Mary Mckay are now affiliated to Washington Univesity in St. Louis, St. Louis, MS.

\section{Declaration of Conflicting Interests}

The author(s) declared no potential conflicts of interest with respect to the research, authorship, and/or publication of this article.

\section{Funding}

The author(s) disclosed receipt of the following financial support for the research, authorship, and/or publication of this article: This study was supported by the Institute of Human Development and Social Change at New York University.

\section{References}

Alkire, S., \& Foster, J. (2011). Understandings and misunderstandings of multidimensional poverty measurement. Journal of Economic Inequality, 9, 289314.

Blank, R. M., \& Kovak, B. (2008, January). The growing problem of disconnected single mothers (National Poverty Center Working Paper No. 07-28). Ann Arbor, MI: National Poverty Center. Retrieved from http://www.npc.umich.edu/ publications/u/working_paper07-28.pdf

Boyatzis, R. E. (1998). Transforming qualitative information: Thematic analysis and code development. Thousand Oaks, CA: Sage.

Brady, D., Fullerton, A. S., \& Cross, J. M. (2010). More than just nickels and dimes: A cross national analysis of working poverty in affluent democracies. Social Problems, 57, 559-585.

Chase, E., \& Bantebya-Kyomuhendo, G. (Eds.). (2014). Poverty \& shame: Global experiences. Oxford, England: Oxford University Press.

Chase, E., \& Walker, R. (2013). The co-construction of shame in the context of poverty: Beyond a threat to the social bond. Sociology, 47, 739-754. 
Citizens' Committee for Children. (2012, April). Concentrated poverty in New York City: An analysis of the changing geographic patterns of poverty. Retrieved from http:// www.cccnewyork.org/wp-content/publications/CCCReport.ConcentratedPoverty. April-2012.pdf

Dean, M. (2010). Governmentality: Power and rule in modern society (2nd ed.). London, England: Sage.

Dooley, D., \& Prause, J. (2002). Mental health and welfare transitions: Depression and alcohol abuse in AFDC women. American Journal of Community Psychology, 30, 787-813.

Glaser, B. G., \& Strauss, A. L. (2009). The discovery of grounded theory: Strategies for qualitative research. Piscataway, NJ: Transaction.

Goffman, E. (1963). Stigma: Notes on the management of a spoiled identity. New York, NY: Simon \& Schuster.

Gubrium, E. K., Pellissery, S., \& Lødemel, I. (Eds.). (2013). The shame of it: Global perspectives on anti-poverty policies. Bristol, England: Policy Press.

Halpern-Meekin, S., Edin, K., Tach, L., \& Sykes, J. (2015). It's not like I'm poor: How working families make ends meet in a post-welfare world. Oakland: University of California Press.

Hatzenbuehler, M. L., Phelan, J. C., \& Link, B. G. (2013). Stigma as a fundamental cause of population health inequalities. American Journal of Public Health, 103, 813-821.

Houser, L., Schram, S. F., Soss, J., \& Fording, R. C. (2014). From work support to work motivator: Child care subsidies and caseworker discretion in the postwelfare reform era. Journal of Women, Politics and Policy, 35, 174-193. doi:10. 1080/1554477X.2014.890834

Jacoby, A. (1994). Felt versus enacted stigma: A concept revisited: Evidence from a study of people with epilepsy in remission. Social Science \& Medicine, 38, 269274.

Jo, Y. N. (2013). Psychosocial dimensions of poverty: When poverty becomes shameful. Critical Social Policy, 33, 514-531.

Lavee, E., \& Benjamin, O. (2016). "I've got no choice": Low-income mothers' emotional management of caring crisis. Journal of Family Issues, 37, 997-1021.

Link, B. G., \& Phelan, J. C. (2001). Conceptualizing stigma. Annual Review of Sociology, 27, 363-385.

Link, B. G., \& Phelan, J. (2014). Stigma power. Social Science \& Medicine, 103, 2432.

Lister, R. (2004). Poverty. Cambridge, England: Polity.

Mak, W. W., Poon, C. Y., Pun, L. Y., \& Cheung, S. F. (2007). Meta-analysis of stigma and mental health. Social Science \& Medicine, 65, 245-261.

McNamee, S. J., \& Miller, R. K., Jr. (2009). The meritocracy myth (3rd ed.). Lanham, MD: Rowman \& Littlefield.

Miles, M. B., \& Huberman, A. M. (1994). Qualitative data analysis (2nd ed.). Thousand Oaks, CA: Sage.

Newman, K. S. (2000). No shame in my game: The working poor in the inner city. New York, NY: Vintage Books. 
Nicolas, G., \& JeanBaptiste, V. (2001). Experiences of women on public assistance. Journal of Social Issues, 57, 299-309.

Padgett, D. K. (2008). Qualitative methods in social work research (2nd ed.). Thousand Oaks, CA: Sage.

Power, C. A., Cole, E. R., \& Fredrickson, B. L. (2011). Poor women and the expression of shame and anger: The price of breaking social class feeling rules. Feminism \& Psychology, 21, 179-197.

Quillian, L. (2012). Segregation and poverty concentration the role of three segregations. American Sociological Review, 77, 354-379.

Rogers-Dillon, R. (1995). The dynamics of welfare stigma. Qualitative Sociology, $18,439-456$.

Scheff, T. J. (2003). Shame in self and society. Symbolic Interaction, 26, 239-262.

Seefeldt, K. S. (2017). Waiting it out: Time, action, and the process of securing benefits. Qualitative Social Work, 16, 300-316. doi:10.1177/1473325015606188

SocioCultural Research Consultants, LLC. (2015). Dedoose Version 6.1.18 [Web application for managing, analyzing, and presenting qualitative and mixed methods research data]. Los Angeles, CA: Author.

Soss, J., Fording, R. C., \& Schram, S. F. (2011). Disciplining the poor: Neoliberal paternalism and the persistent power of race. Chicago, IL: University of Chicago Press.

Tomlinson, M., \& Walker, R. (2009). Coping with complexity: Child and adult poverty. London, England: Child Poverty Action Group.

U.S. Census Bureau. (2014). 2010-2014 American Community Survey 5-year estimates. Retrieved from https://factfinder.census.gov/faces/tableservices/jsf/ pages/productview.xhtml

U.S. Census Bureau. (2015). Annual social and economic supplement (ASEC) of the Current Population Survey (CPS). Retrieved from https://www.census.gov/ library/publications/2015/demo/p60-252.html

Walker, R. (2014). The shame of poverty. Oxford, England: Oxford University Press. Walker, R., Bantebya-Kyomuhendo, G., Chase, E., Choudhry, S., Gubrium, E. K., Nicola, J. Y., . . . Ming, Y. (2013). Poverty in global perspective: Is shame a common denominator? Journal of Social Policy, 42, 215-233. 